Las distintas actitudes de los traductores ante el poema con que comienza una de las historias de Mil y una noches se ponen en relación con dos hechos relevantes que tuvieron lugar en las décadas centrales del siglo xx: la labor de traductores académicos y la interpretación psicoanalítica de la obra. Ambos favorecieron tanto el respeto a la integridad del texto como la apreciación de la estructura general de la obra. Se examinan hechos e hipótesis relativos a 1) la naturaleza narrativa de las Mil y una noches, 2) sus traslados a varias lenguas en los tres últimos siglos, 3) la retraducción de los clásicos y 4) el carácter histórico del fenómeno traductor.

PALABRAS Clave: Mil y una noches, retraducción, clásicos, historia, narratología, texto, psicoanálisis.

\title{
La integridad del original en retraducción (acerca de un poema de Mily una noches)
}

Salvador Peña Martín

Universidad de Málaga
The completeness of the original text in retranslation (on a poem in One Thousand and One Nights)

The different attitudes of the translators toward the opening poem in one of the stories in One Thousand and One Nights are linked with two relevant facts which took place during the mid decades of 20th century, namely the work of academic translators and the psychoanalytic interpretation of the book. Both favored the respect for the integrity of the original text as well as the appreciation of the general structure of the book. Facts and hypotheses relating to 1) the narrative nature of the One Thousand and One Nights, 2) its translations to other languages in the past three centuries, 3) the retranslation of the classics, and 4) the historical nature of the translational phenomenon, are discussed.

KEY WORDS:One Thousand and One Nights, Retranslation, Classics, History, Narratology, Text, Psychoanalysis. 


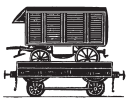

Se recordarái que Mil y una noches (Noches, en adelante) consiste en un conjunto de historias encuadradas por la de un monarca, Shahriar. A causa de una traición de su esposa (que celebra una orgía con sus esclavos en palacio), este se convierte en el asesino de las jóvenes con las que mantiene relaciones sexuales cada noche. Hasta que Shahrazad pone fin a la situación narrándole historias también por las noches. Las vicisitudes textuales de la obra son ciertamente complejas (Reynolds, 2006). Limitémonos a señalar, sin entrar en ellas, que desde el siglo XIX domina, entre las versiones árabes existentes, la recensión egipcia, caracterizada por su larga extensión y fiabilidad, por más que esta se haya puesto también en entredicho (Khawam, 2007).

La cuestión de hasta qué punto podemos considerar las Noches una unidad y cuál sería el eje sobre el que se construye el texto ha sido recientemente tratada por Jullien (2016), para quien existe un estrecho vínculo entre las historias individuales y el conjunto, garantizado por la historia marco, la de Shahrazad y Shahriar. La investigadora francesa añade que, según cuál sea la importancia que se atribuya a ese vínculo, se privilegiará o minimizará la eficacia política y moral de la recopilación, lo que vale para los lectores, los críticos y los traductores; y se muestra convencida de que la obra tiene un significado unitario, por encarnar «la eterna quimera del intelectual: actuar sobre el mundo por medio de las palabras» (Jullien, 2016: I6I; la traducción es mía).

La unidad narrativa de las Noches compete, en efecto, a la historia de la traducción. Vamos a comprobarlo a partir de un pasaje concreto, un poema que ha recibido muy distinto tratamiento por parte de traductores a distintas lenguas,

I El presente estudio se enmarca en el proyecto de $\mathrm{I}+\mathrm{D}$ «La traducción de los clásicos en su marco editorial: una visión transatlántica», referencia FFI 20I3-4I743-P. con la finalidad de contribuir al conocimiento de las Noches, la retraducción de los clásicos y los límites que los traductores se ponen a la hora de intervenir en los textos que vierten. La convicción de que existe un mensaje principal en las Noches, o sea, un discurso elaborado que subyacería a todas las historias, es un factor pertinente para las políticas de traducción seguidas con el clásico árabe.

En la noche 37I de la recensión egipcia (Alf layla, I936: I, 369; Alf layla, I999: I, 6ri; MacNaghten, I839: 2, 347) comienza la historia de los amores apasionados de la joven al-Ward fî-1-Akmām y el príncipe Uns al-Wuğūd, que se muestran bien dispuestos a arrostrar circunstancias adversas para estar juntos. Es la narración I04 de las concordancias de Marzolph y van Leeuwen (2004), y, según Garcin (2016: 89-92), pudo redactarse en el Egipto otomano, a mediados del siglo XVI, aunque incorpora elementos más antiguos, mamelucos y anteriores. Comienza con una caracterización de la protagonista femenina, al-Ward fì 1-Akmām, de quien se destacan su formación humanística, su belleza y su afición a entretenidas tertulias donde se consumía alcohol. Ello se completa con un poema, incidental y compuesto ad hoc, y no, como ocurre también a menudo en las Noches, de una pieza ajena a estas y que se encaja en la historia de que se trate, no siempre con el mismo éxito. Es el siguiente texto árabe, del que veremos numerosas versiones:

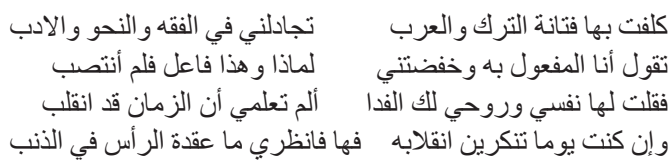

Durante el siglo XIx las traducciones castellanas de las Noches dependían o bien de la francesa de Antoine Galland, publicada en 
I704-I715, o bien de la alemana de Gustav Weil, de 1865. Galland se basó en un manuscrito del siglo xiv o xv (Grotzfeld, r996-97), donde no se recogía la historia que nos interesa. Por su parte, Weil dependía en gran medida de la recensión tunecina (editada en Breslavia), y en ella sí que figuraba la historia, pero con algunas diferencias, entre ellas, otro poema (diferente al citado). La versión de Weil, por tanto, ofrece este, que apenas añade nada a la caracterización del personaje, y que pasó a las versiones españolas intermediadas por la alemana. Algunas siguen publicándose en la actualidad sin mención de traductor $\mathrm{u}$ otros datos que nos permitan datarlas documentalmente en el siglo xIx. Con todo, y a título ilustrativo, he aquí la traducción de dicho poema (el «tunecino»), en una versión de las Noches intermediada por el alemán (Anónimo / Weil 20r4: 2, 80I): «Asoma como la luna / de luceros coronada, / cuando con vivos detalles / las densas nubes realza: / su faz despejada en mi cariño / festivos rasgos derrama, / cual niño que el jilguerillo / asido en su mano halaga».

En el siglo xx las Noches solían trasladarse al castellano a partir de la recensión egipcia (en la edición de Calcuta o de Bulaq), si bien no siempre directamente del árabe, y en dichos originales árabes el poema en cuestión, muy distinto, es el correspondiente al texto árabe ofrecido más arriba. Es un texto muy elaborado y que aporta dos elementos de relieve: una consideración sobre el paso del tiempo y un dato importante que añadir a la caracterización de la protagonista: la llamada al-Ward fî 1-Akmām tenía experiencia en el ejercicio activo y desenfadado del sexo con otras personas. En torno a I920 la editorial Prometeo de Valencia fue publicando las entregas de la versión castellana de las Noches, firmada por Vicente Blasco Ibáñez, a partir de la francesa de Joseph Charles Mardrus, donde los lectores de castellano podían acceder por primera vez al contenido del poema de la recensión egipcia (Blasco / Mardrus, $c a$. I920: I0, 92):

¡Estoy prendado de la seductora! ¡Encantadora de turcos y árabes, conoce todas las finuras de la jurisprudencia, de la sintaxis y de las bellas letras!

Así es que cuando discutimos ambos acerca de estas cosas, he aquí lo que me dice á veces la maligna:

« Yo soy agente pasivo, y tú te obstinas en ponerme en caso indirecto! ¿Por qué? ¡En cambio, dejas siempre en el acusativo á tu régimen, cuya misión es ser activo, y jamás le otorgas el signo de la erección!»

Yo le digo: «iNo sólo te pertenece mi régimen, ¡oh mi señora! sino también mi vida y toda mi alma! Pero no te asombres ya de este trueque de papeles. Hoy cambiaron los tiempos y se trastornaron las cosas.

No obstante, si a pesar de lo que te digo no quieres creer en tal cambio, ¡no dudes más y mira mi régimen! ¿ No has notado que el nudo de la cabeza lo tiene en la cola?»

El poema, humorístico, salaz y rebuscado, entronca con la tradición consistente en aludir a contenidos sexuales con tecnicismos gramaticales, de la que tenemos otra muestra en la noche 971, en una historia diferente. La equiparación paródica entre gramática y actividad sexual era común a las literaturas árabe y latina tardía, lo que ya puso de relieve Curtius (I948: 4I6), aduciendo precisamente este segundo ejemplo, a partir de la versión alemana de Enno Littmann, un arabista académico, por cierto, publicada en I92I-I928. Este último, al igual que Mardrus (de quien dependía Blasco), y dado que su traducción se basaba en la recensión egipcia, incluye el poema en cuestión, pero solo parcialmente, pues vierte solo los dos primeros hemistiquios, omitiendo, pues, los versos con alusiones sexuales y lo relativo al tiempo y los cambios (Littmann, 2004: 3, 385): «Sie lieb ich; sie bezaubert die Türken und Araber all;

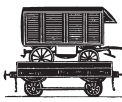

261 


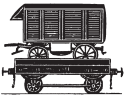

262
/ Sie mißt sich mir Im Recht, in Grammatik und Bildung zumal». En nota al pie, Littmann justifica su actuación por la imposibilidad de reproducir en alemán los juegos de palabras sobre los que se construyen los versos en cuestión: «Hier folgen im Arabischen noch drei Verszeilen, die wegen der Wortspiele zwischen Ausdrücken der Grammatik und des Liebeslebens im Deutschen nicht wiedergegeben werden können».

Hay que darle, en parte, la razón al traductor y orientalista alemán, que, en realidad, da muestras de rigor filológico: la traducción de esos versos había de ocasionar pérdida. Y, sin embargo, ya sabemos que Mardrus (I9or: 8, 8), quien apreciaba mucho el contenido salaz de las Noches, los trasladó al francés, permitiendo así que Blasco los vertiese al castellano, sin mayor creatividad de este. Como muestra, confróntese el comienzo del tercer verso, al que se ajustó el novelista valenciano: «Je suis agent passif, et tu t'obstines à me mettre au cas indirect. Pour quoi cela ? Par contre, tu laisses toujours à l'accusatif ton régime [...]». Ignoro si fue la supuesta intraducibilidad lo que animó al siguiente traductor al castellano (siempre a partir de la recensión egipcia) de las Noches, Rafael Cansinos Assens (I954-55), a servirse, de nuevo, del poema alternativo, que ya vimos en la versión anónima de la alemana de Weil («Brilla igual que la luna en el límpido cielo / vestida de sus trenzas, negras como la tinta [...]»), limitándose a aclarar en nota que depende, en ese punto, «de la ed. de Breslau», es decir, del manuscrito de Túnez. Esto podría extrañar dado que Cansinos, según él mismo declara, se basaba en la recensión egipcia, sobre todo en la edición de Calcuta. Cansinos coincidía, en la omisión del poema «egipcio», con ilustres traductores al inglés que, como él, partían de la recensión egipcia. Veámoslo.
En primer lugar, hay que considerar la versión, publicada en I838-840, de Edward W. Lane, a quien Borges (I953: II9) caracterizó por sus «remilgos puritanos». No sorprende, pues, que suprimiera el poema gramático-sexual, sin dar explicaciones ni sustituirlo por otro, en su versión, directa pero muy cercenada (Lane I853: 49I). Sí que resulta extraño que las dos versiones inglesas que siguieron, la de John Payne (de I882-I884) y la de Richard Burton (de I885-I888), que expresan afanes de fidelidad, prescindan del poema egipcio en cuestión y lo sustituyan, como más tarde haría Cansinos, por la alternativa tunecina. Es lo que hizo, primero, Payne (I90I: 4, I74), quien vuelve al poema que he tildado de anodino ( She shines out like the moon at full [...]»), sin of recer justificación alguna. Visto lo cual, y habida cuenta de que se ha acusado a Burton de haber plagiado a Payne (Zipes, 2007: 57), cuyo texto se limitó a retocar, solo cabía esperar que aquel recurriera de nuevo a la alternativa tunecina ( Like moon she shines amid the starry sky [...]»); aunque, ahora sí, justificándose en nota al pie (Burton I885: 5, 32): "These lines are from the Bresl[lau] Edit[ion] (v. 35.) The four couplets in the Mac[Naghten] Edit[ion] are too irrelevant». Aclaremos que la edición de MacNaghten aludida es la segunda de Calcuta (1839), siempre a partir de la recensión egipcia.

Después de Cansinos, y a pesar de los precedentes en inglés, los traductores al castellano que han partido de la recensión egipcia (ya sea Calcuta o Bulaq) no han vuelto a eliminar el poema "demasiado irrelevante», según opinaba Burton. Ello puede deberse a que en las décadas centrales del siglo xx fueron arabistas universitarios quienes comenzaron a hacerse cargo, con exclusividad, de la traducción de las Noches, aplicando un prurito de rigor que podríamos atribuir a su formación filológica. En los años 
sesenta se publicaron dos meritorias versiones castellanas, la de Juan Vernet (primera edición, r964) y la de Juan Antonio Gutiérrez-Larraya y Leonor Martínez Martín (primera edición, I965). Antes que ellos un equipo de traductores igualmente universitarios (entre ellos, Virgina Vacca para el texto que estamos considerando) habían publicado la traducción italiana que dirigió F. Gabrieli (primera edición, I948). Se citan las tres a continuación, por orden cronológico de sus primeras ediciones (Gabrieli, 2006: 2, 35I; Vernet, 2005: 2, I87; Gutiérrez-Larraya y Martínez, I965: 2, I99):

Mi sono innamorato di lei, seduttrice dei Turchi e degli Arabi. Ella disputa con me di diritto, di grammatica e di letteratura.

Dice: - Io sono l'oggetto, eppure mi hai messa al genitivo; codesto è l'agente, perché mai è al caso retto? [En nota al pie: «Sotto questa terminología grammaticale non è difficile riconoscere il doppio senso lubrico, come anche nell'ultimo verso».]

E io le risposi: - L'anima mia e il mio spirito siano il tuo riscatto: non sai forse che il tempo è andato tutto sossopra?

E se mai disconoscessi il suo capovolgimento, guarda un po' come mai il nodo della testa è nella coda!

Me he enamorado de la que es la seducción de turcos y árabes. Discute conmigo de derecho, de gramática y de literatura.

Dice: "Yo estoy en acusativo, pero tú me pones en genitivo; ¿por qué a ese que es el agente no le pones en acusativo?».

Le respondo: « $i$ Que mi cuerpo y mi alma constituyan tu rescate! ¿Es que no sabes que el tiempo cambia?

Si un día niegas los cambios del tiempo fíjate el nudo de la cabeza con la cola». [En nota al pie: "Los versos segundo y cuarto contienen, bajo la forma de la terminología gramatical, traducida al pie de la letra, una serie de alusiones a la vida sexual».]
Me enamoré de ella, seducción de los turcos y árabes. Discute conmigo de derecho, gramática y literatura, diciendo:

"Yo soy el acusativo, aunque me pusiste en genitivo; éste es el sujeto, ¿por qué nunca está en caso directo?» [En nota al pie: «Este vocabulario gramatical encierra alusiones amorosas fáciles de comprender si se recuerda el valor de los casos en la declinación».]

Le contesté: «Sean tu rescate mi alma y mi espíritu. ¿Acaso ignoras que el tiempo se ha trastocado?

Por si desconoces su trastorno, repara en que nunca el nudo de la cabeza está en la cola».

Mención aparte merece una tercera traducción castellana, semejante a las tres anteriores, la contenida en la «antología» de las Noches elaborada por Julio Samsó, de nuevo un traductor universitario de mérito académico, y publicada una década después. Esta versión reducida, según declara el traductor (Samsó, I975: 19), se realizó asimismo a partir de la recensión egipcia (Bulaq, en concreto), e incluía la siguiente versión del poema:

Me he enamorado de ella, la que seduce a turcos y árabes; discute conmigo sobre derecho, gramática y literatura.

Me dice: si soy el objeto, ¿por qué me pones en genitivo? Si éste es el sujeto, ¿por qué está en acusativo?

A ello he respondido: que mi alma y mi vida sean tu rescate, ¿no sabes que los tiempos han cambiado?

Si un día llegas a negar este cambio, mira entonces el nudo que forman la cabeza y la cola.

Y merece atención especial porque, en su nota a dichos versos, Samsó (I975: 399) afirma que «[...] desentonan con la atmósfera general del cuento y tienen todo el aspecto de una interpolación». Esta opinión no cabe ni apoyarla ni refutarla fehacientemente, pero sí conviene subrayar, por un lado, que el traduc-

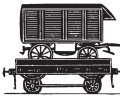

263 




tor muestra el rigor filológico que le impide eliminar un fragmento que juzga sospechoso, $y$, por otro, que la afirmación de que el poema «desentona» se realiza en referencia a la historia individual en que se halla, y no a las Noches en su conjunto. $\mathrm{Y}$ es que la idea de la coherencia de estas, concebidas como obra unitaria, comenzó a extenderse entre los especialistas precisamente un año después de que se publicara la versión de Samsó, y a ella podrían haberse atenido los traductores posteriores, si nos basamos en su tratamiento del poema en cuestión, y no atribuimos su proceder a rigor filológico una vez más (todos ellos pertenecen asimismo al ámbito académico universitario). En efecto, los traductores al castellano o a otras lenguas europeas que han partido de la recensión egipcia han seguido traduciendo el poema, sin que aparentemente hayan dudado de que sea relevante o genuino (no interpolado). Aparece, así, sin más, en la versión catalana de Cinca y Castells (I995: 2, 244), la francesa de Bencheikh y Miquel (2005: 2, I04), la inglesa de Lyons (2008: 2, I49) y la castellana de Peña (2018: 2, 369), que reproduzco en ese mismo orden:

A mi també m'enamorà

la formosa i gentil poncella

que als àrabs $i$ als turcs encisà.

I fins i tot puc parlar amb ella

des lleis y de mots, i d'arts bellas!

Digué : «Jo soc acusatiu, i tu em vols veure genitiu?

Però si aquest nominatiu no vol pas ser acusatiu !»

Responc: «Sóc teu en cos i ànima.

No saps que tot pot canviar?

Si no t'ho prens amb temperancia, veuras els extrems a tocar.
J'aime une fille qui rend fous Turcs et Arabes. Belles-lettres, grammaire, droit : en tout, elle me tient tête.

Elle me dit : « Me voici complément et je suis ton objet !

Pour quoi donc celui-ci ou tel autre est-il sujet, sans que je sois, moi aussi, marquée de ce signe?»

Et moi je lui répons : «Dispose de ma vie, dispose de mon âme !

Ne connais-tu donc pas les caprices du temps?

Si tu voulais, un jour, refuser de les voir, considère qu'en tout, le principe est lié à la fin. »

I am in love with the greatest enchantress among Turks and Arabs;

She argues with me on religious law, grammar and literature.

'I am the grammatical object,' she says, 'but you put me in the genitive;

Why is that? This is a subject, so why is it in the accusative?'

I said to her: 'My life and my soul are your ransom;

Do you not know that time is full of changes?

If you find yourself doubting this,

See how the head of a sentence can be fitted to its tail.'

Turcos y árabes se pierden

por esa linda mozuela,

que conmigo polemiza

de leyes, letras y lengua.

«Si soy - me dice - tu objeto,

¿por qué me tienes sujeta?

$\mathrm{Y}$, si lo que veo es regente, ¿no debiera yo estar recta?».

«Mi alma y mi vida — respondo-

por tu bienestar yo diera.

Y, si acaso no esperabas

del Tiempo alguna sorpresa, observa cómo la cola

se junta con la cabeza». 
A la vista de ello, resulta evidente que la afirmación de E. Littmann: el poema ofrece graves dificultades para su versión, resulta muy discutible; o, en todo caso, que, durante el tiempo transcurrido, casi un siglo, ha cambiado lo que es aceptable (recursos «extraños») o inaceptable (recorte de fragmentos) en traducción de clásicos. Pero también es preciso considerar la justificación de Burton, quien suprimió el poema arguyendo que es «too irrelevant» («demasiado poco pertinente»), afirmación arriesgada y que implica que el traductor, convertido en editor, corrige el texto. Pero ¿tenía razón Burton? ¿Podía eliminarse el poema sin atentar contra la estructura de la obra, sin mermar algún aspecto narratológico o del mensaje de las Noches?

Hace más de cuarenta años que el psicoanalista Bruno Bettelheim publicó su estudio sobre los cuentos de hadas, The Uses of Enchantment. En lo relativo a las Noches, Bettelheim (I992 [1976]: I24-I25) observa que Shahrazad, gracias a su maestría como cuentacuentos, consigue que el rey Shahriar se cure de su odio a las mujeres. En las Noches asistimos, según Bettelheim, a una catarsis debida a tres años de relatos. En la década siguiente Clinton (1985) afirma que las Noches es una historia de locura y terapia por la palabra, y ensaya un psicoanálisis de Shahriar (incluyendo la hipótesis de que su trauma fue causado por su propia madre); y concluye que, la obra en conjunto es una auténtica unidad narrativa. Grandguillame y Villa (1989) insisten: las Noches no son una antología de relatos como las de Perrault o Grimm, sino que suponen un proyecto de conjunto, una narración «a largo plazo». Todas estas conclusiones las retomó el psicólogo y antropólogo Fethi Benslama (2002) en su psicoanálisis del islam.

Más cerca de la narratología, Zipes (2007 [1999]: 59-62) argumenta que, aunque los relatos de las Noches fuesen elaborados por distintos autores, es Shahrazad quien les proporciona su razón de ser: curar al rey. Y Sallis (I999: 95), del mismo modo, sostiene que las imágenes, recomendaciones y experiencias que se suceden durante tres años, gracias a Shahrazad, se parecen a lo que llamamos psicoterapia. E1 asunto acabó interesando a psiquiatras y terapeutas de la palabra. En un estudio sobre los traumas sexuales, Marvasti (2004: I69) afirma que el recurso a la narración de historias con fines educativos y curativos tiene uno de sus más antiguos precedentes en las Noches. Y Lee (20Io), justificando la terapia por medio de las humanidades, explica cómo, del intercambio de relatos entre terapeuta y cliente, surgen relatos alternativos. Sobre el modo en que esto ocurre aporta, de nuevo desde la investigación literaria, algo de luz Abu Baker (20Ir: 94), quien sostiene que en las historias de Shahrazad hay mensajes subliminales que afectan a la mente de Shahriar. También desde la perspectiva de los estudios de la mujer se ha abordado el asunto, llegando a resultados parecidos. Montero (20Ir [ंi1998?]) señala que la labor de Shahrazad permite al monarca superar su instinto asesino; en tanto que Frankel (2010: I06) y al-Samman (2015: I72) vuelven a asumir lo que esta llama la «misión curativa de Shahrazad». El asunto se ha seguido extendiendo a través de escritos publicados en la prensa. Tanto Peñaflorida (2003) como Chebel (20I2) repiten que Shahrazad cura al rey loco.Y, de nuevo en la literatura especializada, la identificación de Shahrazad como psicoterapeuta avant la lettre la da por adquirida Warner (20II).

El asunto, sin embargo, no se había enfocado desde la perspectiva de la traducción, y no me refiero tanto a la terapia de palabras en sí misma o a la interpretación psicoanalítica de las Noches, sino a la unidad narrativa de la obra, que, de existir, como todo indica, implicaría que los elementos constituyentes no son fácilmente

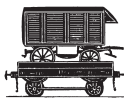

265 


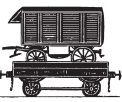

prescindibles. Volvamos a la historia principal y recordemos que el rey asesino, Shahriar, experimenta dos cambios sustanciales ante nuestros ojos. Al comienzo de la obra ya se nos informa de que «era juez equitativo para sus vasallos» (Cansinos, 1954-55, I, 4I5). Más adelante, la traición de su esposa lo empuja a sus crímenes diarios. Pero la intervención de Shahrazad consigue, al final del libro, restituirlo a su ser. Y el poema «gramático-sexual» de la recensión egipcia, además de destacar la acción del tiempo, presenta, al principio de la historia, una imagen muy específica de la protagonista, al-Ward fî 1-Akmām (frivolidad, libertad sexual), que cambiará radicalmente cuando cae enamorada del príncipe. Ello constituye una imagen reducida del segundo cambio experimentado por Shahriar (de la promiscuidad amoral a la monogamia ordenada). Si en otra historia de las Noches se afirma que «no pasan el día y la noche sobre cosa alguna sin introducir en ella algún cambio» (Cansinos, 1954-55: 1, 1381), esta que nos interesa acaba precisamente con una invocación a Dios, el único ser libre de transformaciones: «jGloria a Aquel que ni cambia ni desaparece y al que vuelven todas las cosas!» (Samsó, 1975: 282). El cambio de personalidad de un ser humano, pues, es perfectamente posible.

Hay que afirmar, en conclusión, que las traducciones constituyen fenómenos sociales históricos. Su historicidad es doble. Primero, las traducciones están de alguna manera determinadas por su aquí y a su ahora, y sujetas a los cambios de mentalidad, de imaginario, de ideologías. Además, las versiones, y, sobre todo, las re-traducciones, se producen en el marco de la historia interna de la propia traducción. La visión psicoanalítica de las Noches se genera en una hermenéutica propia de la contemporaneidad. Pero ha ayudado a una mejor comprensión estructural de la obra y, por ende, al progreso en la historia de su traducción.
Aunque parece registrarse una creciente tendencia por parte de los traductores a respetar en todo caso la integridad del original, cabe señalar que el texto árabe de las Noches da por sí solo, y con independencia de las corrientes de pensamiento que a él se apliquen, pistas suficientes de cómo ha de tratarse su estructura (como hemos visto en el hemistiquio sobre el paso del tiempo). Las retraducciones de las Noches han ido ajustándose tanto a la integridad textual del original como a su lógica narratológica interna, al tiempo que naturalizaban lo que pudo considerarse extraño en momentos previos; todo lo cual confirma los resultados de la investigación de Desmidt (2009), a saber, que las re-traducciones se ajustan cada vez más al original. Por último, hemos comprobado, una vez más, que el análisis (e incluso la crítica) de un elemento concreto de una obra y su traducción han de realizarse en el marco de la obra en su conjunto.

RECIBIDA EN MARZO DE 2018

ACEPTADA EN MARZO DE 2018

VERSIÓN FINAL DE SEPTIEMBRE DE 2018

\section{REFERENCIAS BIBLIOGRÁFICAS}

Abu Baker, Ahmad M. S. (20II): «Metamorphosis $\&$ the therapeutic function of storytelling», CrossCultural Communication, 7/3, 86-95.

ALF LAYLA (¿i935?): Alf layla wa-layla, [E1 Cairo:] al-Mațba'a al-Sa 'ídiyya.

—(1999): Alf layla wa-layla, Beirut: Dār Șādir.

Anónimo / Weil, Gustav (20I4): Las mil y una noches, Barcelona: Brontes.

Bencheikh, Jamel Eddine y André Miquel (2005): Les Mille et Une Nuits, París: Gallimard.

Benslama, Fethi (2002): La psychanalyse à l'épreuve de l'Islam, París: Aubier.

Bettelheim, Bruno (1992) [1976]: Psicoanálisis de los cuentos de hadas, trad. Silvia Furió, Barcelona: Crítica. 
Blasco IbáÑez, Vicente y Joseph C. Mardrus (ca. 1920): El libro de las mil y una noches, Valencia: Prometeo.

Borges, Jorge Luis (1953): Historia de la eternidad, Buenos Aires: Emecé.

Burton, Richard F. (1885): The Book of the Thousand Nights and $a$ Night, s. 1.: The Burton Club.

Cansinos Assens, Rafael (1954-55): Libro de las mily una noches, México: Aguilar.

Chebel, Malek (20I2): «Qui es-tu, Shéhérazade?», Le Point, 20 de diciembre, $<$ http://www.lepoint.fr/arts/ qui-es-tu-sheherazade-20-I2-2012-I608708_36. php> [consulta: 9-XII-20I7].

Cinca, Dolors y Margarida Castells (I995): Les mil i una nits, Barcelona: Proa.

Clinton, Jerome (1985): "Madness and cure in the Thousand and One Nights», Stvdia Islamica, 6I, IO7-I25.

Curtius, Ernst Robert (1948): Europäische Literatur und lateinisches Mittelalter, Berna: Francke, $2^{\mathrm{a}}$ edición.

Desmidt, Isabelle (2009): «(Re)translation revisited», Meta, 54/3, 669-683.

Frankel, Valerie Estelle (2010): From Girl to Goddess, Jefferson (Carolina del Norte): McFarland and Company.

Gabrieli, Francesco (dir.) (2006): Le mille e una notte, Turín: Einaudi.

Garcin, Jean-Claude (20I6): Les Mille et Une Nuits et l'Histoire, París: Non Lieu.

Grandguillame, Gilbert (I989): «Les Nuits parlent aux hommes de leur destin», Corps Écrit, 3 I (L'Arabie Heureuse), 47-62.

Grotzfeld, Heinz (1996-97): "The Age of the Galland Manuscript of the Nights», Journal of Arabic and Islamic Studies, I, 50-64.

Gutiérrez-Larraya, Juan Antonio y Leonor Martínez Martín (1965): Las mil y una noches, Barcelona: Vergara.

Jullien, Dominique (20I6): «La guérison par l'exemple: morale, politique et exemplarité dans les Mille et Une Nuits et leur hypertexte», Féeries, I3, I45-I63.

KHAWAM, René R. (2007): «Introducción», en Las mil y una noches, ed. René R. Khawam, trad. Gregorio Cantera, Barcelona-Buenos Aires: Edhasa.
Lane, Edward William (1853): The Arabian Nights' Entertainments, New Edition, Boston: Little, Brown and Company.

LEE, Minyong (20I0): «Storytelling as therapy and its two modalities: Myth and Arabian Nights», Journal of Humanities Therapy, I, I45-I56.

Littmann, Enno (2004) [192I-28]: Die Erzäblungen aus den Tausendundein Nächten, Fráncfort del Meno-Leipzig: Insel.

MacNaghten, William Hay (I839): Alif Laila, or Book of the Thousand Nights and one night, commonly known as The Arabian Nights, Calcuta: The Baptist Mission Press.

Marvasti, Jamshid A. (2004): Psychiatric Treatment of Victims and Survivors of Sexual Trauma, Springfield (Illinois): Charles C. Thomas.

Marzolph, Ulrich y Richard van Leeuwen (eds.) (2004): The Arabian Nights Encyclopedia, Santa Bárbara-San Diego-Óxford: ABC-CLIO.

Montero, Rosa (20II) [¿i998?]: «Contra la muerte: Las mil y una noches», en El amor de mi vida, Barcelona, Penguin Random House, posiciones 3133-3289 (versión digital Kindle).

Peña Martín, Salvador (2018): Mil y una noches, $2^{\mathrm{a}}$ edición, Madrid: Verbum.

Peñaflorida, Ainhoa (2003): «Tiempo de Sherezade», El País, 2 de abril, <https://elpais.com/ diario/2003/o4/o2/paisvasco/I0493I24I6_850215. html> [consulta: I8-XII-2OI7].

Reynolds, Dwight F. (2006): "A Thousand and One Nights: A history of the text and its reception", en Roger Allen y D. S. Richards (eds.), Arabic Literature in the Post-Classical Period, Cambridge University Press, pp. 270-291.

SAllis, Eva (1999): Sheherazade Through the Looking Glass, Londres-Nueva York: Routledge.

Al-Samman, Hanadi (2015): Anxiety of Erasure: Trauma, authorship, and the diaspora in Arab women's writings, Syracuse University Press.

Samsó, Julio (1975): Antología de Las Mil y Una Noches, Madrid: Alianza.

VERnET, Juan (2005): Las mil y una noches, Barcelona: Galaxia Gutenberg-Círculo de Lectores.

Warner, Marina (20II): Stranger Magic: Charmed states $\mathcal{\sigma}^{\circ}$ the Arabian Nights, Londres: Vintage.

Zipes, Jack (20072) [1999]: When Dreams Came True: Classical fairy tales and their tradition, Nueva York-Abingdon: Routledge.

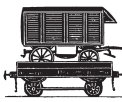

